\title{
INDUSTRIAL ECOLOGY FOR EGYPT: A CONCEPTUAL FRAMEWORK OF THE PLANNING PROCESS
}

\author{
Aboulfetouh Saad Shalaby
}

Faculty of Urban and Regional Planning, Cairo University, Egypt

\begin{abstract}
Egypt has recently embarked upon preparing an ambitious national urban plan for the year 2050, with industry as one of its proposed economic bases. Yet, it is widely agreed that existing industrial zones in Egypt are not sustainable. Future industrial developments are prone to the same destiny, if the process of founding the existing industrial zones is going to control the development of future ones. In this regard, the Egyptian government has taken some steps to incorporate industrial ecology to enhance sustainable development.
\end{abstract}

Presently, the question which poses itself is: to what extent have these steps considerably changed the process through which industrial zones are founded in Egypt, and what are the factors which help shape this process? An answer to this question is necessary for a real shift towards industrial ecology.

This research attempts to construct a conceptual framework of the process through which eco industrial parks could be normatively developed. This framework is seen in this paper as a first step towards understanding the current process of establishing industrial zones in Egypt, and developing it, if needed. To construct this framework, this theoretical study analyses normative and empirical literature available in the field of industrial ecology, governance and sustainable development, looking for overarching governing understandings, contextual settings, and planning processes through which industrial ecology could potentially be brought to reality. A synthesis of these dispersed ideas/practices into a coherent framework constitutes the contribution of this research.

Keywords: Planning process, industrial ecology, sustainable development, governance.

الملخص

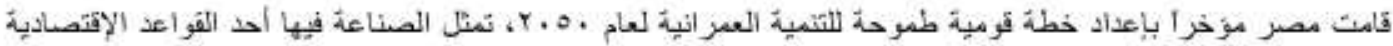

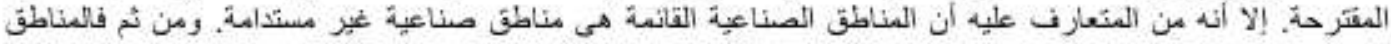

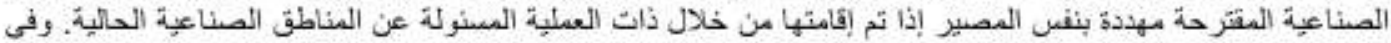

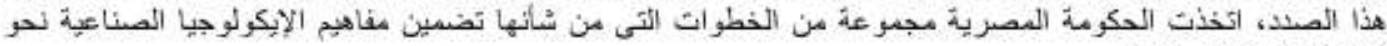

تحقيق التثمبة المسنيدامة.

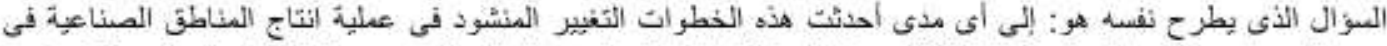

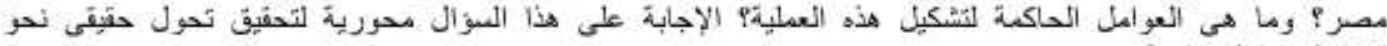
الإبكولو جبيا الصناعنة.

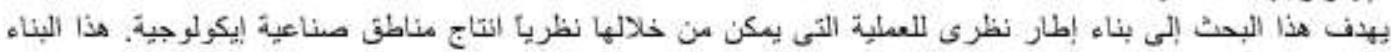

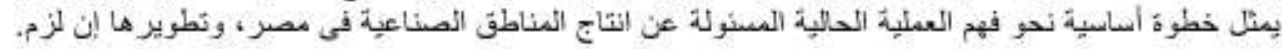

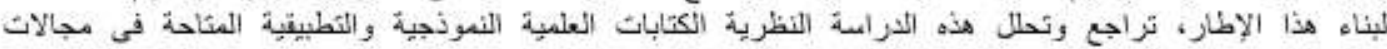

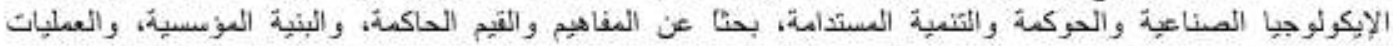

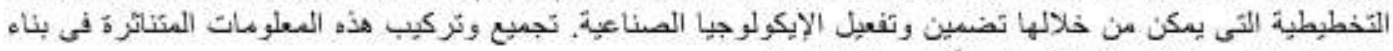

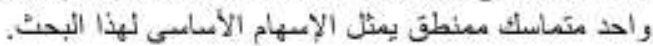
الكلمات الدالة: العملية التخطبطبة، الإبكولوجيا الصناعبة، الثنمبة المسئدأمة، والحوكمة. 


\section{INTRODUCTION}

Egypt has recently set out to prepare a new national urban development map to accommodate double the current population for the year 2050. Within this intended national urban plan, industry is one of the main proposed economic bases ${ }^{1}$ (Madbouly, 2011). Yet, it is widely argued that existing industrial developments in Egypt are not sustainable (Shalaby, 2003; ESCWA, 2003). Environmental conditions are expected to get worse, if the proposed industrial zones are going to follow the footsteps of the existing ones. There is, therefore, an utmost need to look for ways to bring development and environment together (Shalaby, 2003). A new sustainable development strategy, which has the ability to overcome the current and the expected dilemmas of protecting the environment, has become a necessity (ESCWA, 2003).

Industrial ecology ${ }^{2}$ (IE), within the general frame of sustainable development, is the most recently proposed conception for planning for industrial development (Shalaby, 2003). It is one important way of how industry could contribute towards sustainability (Cervantes, 2007; Geng and Hengxin, 2009; Kim, 2007). For Gibbs and Deutz (2005), it is the science of sustainability. Collectively, IE represents precisely one of the main paths that could make the concept of sustainable development operational in an economically feasible way (Erkman, 1997). Relevant practices and experiences in the developed world have proved that there is a degree of efficiency to development through the application of IE (Geng and Yi 2005). IE is, therefore, an important conception to adopt, as it does not only save the environment, but also cut industrial management costs. Hence, it could be marketed easily to governments as well as investors (Shalaby, 2009b).

In this regard, since the 1990s, the Egyptian government has made some institutional arrangements in favour of environmental protection, and has announced taking steps to effectively incorporate sustainable development, the most important of which are:

1. Establishing Ministry of State for Environmental Affairs, and amending the environmental law to give wider mandates to, and restructure, the Egyptian Environmental Affairs Agency (Shalaby, 2009a), the tasks of which are:

- Preparing national plans for environmental protection, and emergency plans for natural disasters.

- Implementing piloting projects.

\footnotetext{
${ }^{1}$ The same meaning was confirmed through a phone interview with Prof. Dr. Samy Amr, a member of the multidisciplinary team assigned by the General Organisation of Physical Planning to develop the national urban development map. He clearly indicated that competitive projects of industry and commerce are going to be among the leading economic bases for the new proposed national urban plan.

2 Industrial ecology is concerned with the shifting of industrial processes from linear (open loop) systems, in which resource and capital investments move through the system to produce waste, to a closed loop system where wastes can become inputs for new processes (Wikipedia, 2011a).
} 
- Formulating principles and procedures of environmental impact assessment.

- Drafting environmental laws, regulations, standards and safe pollution rates.

- Supervising the Environmental Protection and Development Fund.

- Raising awareness and preparing environmental capacity building programs.

2. Forming an ad hoc inter-ministerial council to encourage institutional coordination, and establishing environmental units in some line-ministries to achieve and maintain inter-sectoral coordination (ESCWA, 2003).

3. Establishing the National Committee for Sustainable Development (NCSD) to prepare policies, plans, and legislative reforms required to lay the foundation of sustainable development in Egypt (Shalaby, 2009a).

4. Initiating a reformation process of institutional and legislative frameworks ${ }^{3}$, to overcome bureaucracy and improve investment atmosphere (Shalaby, 2009a).

5. Supporting the establishment of the Egyptian National Council for Competitiveness (ENCC) as a non-governmental forum for dialogue among different stakeholders to advise on the reformation process of the legislative framework (ENCC, 2009).

6. Enacting Planning \& Building law 119 with a special mention of sustainable development as a central theme, and assigning the General Organisation of Physical Planning (GOPP) as the official body responsible for fostering sustainable development (Shalaby, 2009a).

7. Initiating the Egyptian Program of Environmentally friendly Industrial Cities (Shalaby, 2003), including the initiation of a transformation plan of existing factories to become environmentally friendly factories (Masrawy, 2010).

Hence, there is a paramount need to examine the extent to which these steps have considerably changed the process through which industrial zones are founded, towards incorporating industrial ecology (IE). In addition, identifying the factors which influence/shape the current prevailing process is essential for the development of the process as well as its product. In tune, Shalaby (2009d) contends that theorising upon the current process of founding industrial zones in Egypt is lacking. This lack is not particular to the Egyptian case though. International literature reviewed shows that empirical testing is needed to examine the performance of actions taken towards sustainability worldwide, and the extent to which these actions have caused a shift from government to governance ${ }^{4}$. In tune, international literature shows that a theory of governance for sustainable development/IE still does not exist (Jordan, 2008). A gap between the concept of IE and its implementation continues to exist, calling for social sciences to bridge it (Vermeulen, 2007).

3 Booz-Allen, Guillotine and Errada are examples of plans that have been recently adopted by the Egyptian government as part of this reformation process (Shalaby, 2009a).

${ }^{4}$ Governance is the emerging patterns of governing efforts/processes which encompass formal as well as non-governmental mechanisms/activities. These patterns are not limited to time, scale or place (Jordan, 2008). 


\section{RESEARCH OBJECTIVES}

This research attempts to construct a conceptual framework of the process through which eco industrial parks could be potentially developed. This framework is seen as a first step towards, firstly, understanding and evaluating the current process through which industrial zones are founded in Egypt, and, secondly, developing it, if needed, to become more sustainable. The paper does not present this framework as a recipe that is placeless or timeless. Being a collection of mosaics, this framework is evidently inapplicable to any context. A grand theory of governance for sustainable development is extremely doubtful (Shalaby, 2009c). The framework is rather a catalyst that could initially help in collecting data relevant from the local Egyptian context. These data are to be then analysed inductively, through a grounded theory approach, towards an understanding of the current process of founding industrial zones, its shaping factors, and the obstacles it faces. Further, the ideas presented by this framework could enrich local scholarly as well as societal debates on how to develop the current process towards IE.

\section{RESEARCH METHODOLOGY}

To construct this framework, the paper analyses normative and empirical literature available in the field of IE, governance and sustainable development, looking for overarching governing understandings, contextual settings, and planning processes through which IE could potentially be brought to reality. A synthesis of these ideas/components into a coherent framework constitutes the contribution of this research. This research is considered, therefore, a theoretical study in that it involves the review, critique and integration of theory in existing literature.

\section{RESEARCH STURCTURE}

The paper is organized in five sections. The first presents the overarching understandings which normatively have to govern the formation of the context, and the planning process. The second delineates the necessary set up of the context in relation to its different components such as education and research, institutional and regulatory frameworks, networking, and funding. The third lays down the planning process through which eco industrial parks could be likely developed. Materials reviewed in these three sections take the shape of consecutive points which logically build on each other towards the construct of the framework, which is, then, synthesised as a 'whole' in the fourth concluding section. The fifth proposes possible avenues for future research, towards the fulfilment of the ultimate purpose of this research.

\section{OVERARCHING UNDERSTANDINGS}

This section presents two groups of understandings which normatively govern the formation of the context and the emerging planning process. The first group generally addresses the nature of both, sustainable development, governance and IE 
on one hand, and the local context on the other; and consequently hints to some principles/ideas that have to be considered in setting the context and the planning process to bring about best possible results. The second group identifies the gist of IE along with its major characteristics which have to inform and contribute to the formation of the planning process.

\subsection{General Understandings}

- Sustainable development, governance (Jordan, 2008), and IE (Shalaby, $2009 \mathrm{~b})$, are all ambiguous terms. Intensive scholarly and societal debates are needed to contextually define these terms (Jordan, 2008).

- Sustainable development is fundamentally a normative idea and achieving it is a complex issue (Jordan, 2008) that is handled in a continuously changing context. Therefore, policies, plans and regulations have to be regularly updated (Geng and Yi, 2005).

- Sustainable development principles related to its three pillars, society, economy and the environment, conflict sharply with one another, and hence require systems of governance that resolve conflicts and reach coordinated policies (Jordan, 2008).

- Governance mode has to be cognizant to its context (Jordan, 2008). Compared with developed nations, developing nations face different environmental, economic and social constraints, and, therefore, have to adopt a different approach to implement IE (Geng and Yi 2005).

- Industrial ecology (IE) is not a system that is merely applicable inside the boundaries of an industrial park (Geng and Yi, 2005), but a culture that the community has to adopt. Sustainable development should not continue to be understood as a mere environmental matter (ESCWA, 2003). IE is, therefore, an interdisciplinary field of studying industrial systems in concert with nature and society (Geng and Yi, 2005). To apply IE, therefore, a long-term, incremental, multidisciplinary, integrated, and coordinated planning approach has to be adopted (Gibbs and Deutz, 2005; Geng and Yi, 2005; Roberts, 2004). The outcome of such an approach has to be flexible and subject to regular scrutiny and potential change (Shalaby, 2009b).

- For a regulatory/legal setup to be favourable, effective and realistic, it has to be not only context-specific, but also case-specific. A shift from a regulationbased to incentive-based approach, or from a prescriptive to proscriptive code of law, is a necessity. Literature reviewed is in favour of a setup which tells people what not to do (as opposed to telling them what to exactly do), and encourages them to achieve good results rather than follow certain steps or abide by insensitive generalised regulations (Roberts, 2004; Shalaby, 2010).

\subsection{IE Understandings}

- The primary concern of IE is industrial symbiosis/cycle closing. The colocation and integration of firms which can use or reprocess the waste of other industries in the same locality is critical to the success of IE (Roberts, 
2004; Gibbs and Deutz, 2005; Tudor et al., 2007; Erkman, 1997; Geng et al., 2009; Singh et al., 2007; Cervantes, 2007; Liwarska-Bizukojc et al., 2009; Kim, 2007). Closed industrial system (Shalaby, 2003), industrial ecosystem (Geng and $\mathrm{Yi}, 2005$ ), industrial round put system, and circular economy (Sterr, 2005) are different terms used to express the gist of IE to imply ideas of lowering the ecological footprint (Shalaby, 2003), mimicking nature, optimizing the use of energy and resources (Geng and $\mathrm{Yi}, 2005$ ), and meeting the challenge of resource depletion (Sterr, 2005).

- In this regard, waste must no longer be seen as something that is harmful, but as a potential resource (Shalaby, 2009b).

- IE works best where there is a strong agglomeration or clustering of establishments that have the capacity to utilise waste as a resource in production. The more intense the agglomeration, the greater are the prospects for innovation and synergies (Roberts, 2004; Tudor et al., 2007; Erkman, 1997; Elabras Veiga and Magrini, 2009). This intensity implies not only variety, but also redundancy, of the agglomerated establishments. According to Sterr (2005), the principle of redundancy has proven to be one of the vital success factors of the natural role model. In other words, for closing the loop in an industrial setting, the number of establishments within an industrial context should not only extend into various branches and inputoutput systems in order to increase the probability that a fitting partner is among them, but it should also provide several species of the same kind.

- Industrial parks have to provide such an opportunity of variety and redundancy (Sterr, 2005). An eco-industrial park (EIP) is a piece of a contiguous fenced property owned and managed as a unit for a community of sharing, integrated industrial and business enterprises (Geng and Yi, 2005; Shalaby, 2003). EIPs encourage mixed land uses, and co-location of manufactures and service providers; and facilitate cogeneration, waste and resource sharing and waste reprocessing (Roberts, 2004). A shift from activity-based to performance-based appraisal is, therein, crucial in the coallocation process of uses/establishments. A performance-based appraisal would permit a business to be located not due to the nature of its activity, but according to its performance and the external benefits it could create (Shalaby, 2009b).

- However, if industrial parks fail short of achieving full industrial symbiosis, industrial regions are powerful counterparts. In fact, the adoption of IE principles on the regional level is argued by some to be more viable than on purely park-based level (Sterr, 2005; Gibbs and Deutz, 2005). Determining these regions ${ }^{5}$, though, will differ from a context to another.

\footnotetext{
${ }^{5}$ Sterr (2005) finds that the market size of the industrial region of Rhine-Neckar, Germany with its roughly 2 million inhabitants is large enough to economically guarantee self sustaining recycling processes within its systemic borders, and generalizes that almost any kind of waste that can be recycled within Germany can also be recycled within the systemic borders of an industrial region like that of Rhine-Neckar.
} 


\section{SETTING THE CONTEXT}

In light of the above-mentioned understandings, this section shows how to make the context normatively ready to incorporate and implement IE. The section sets the societal will central to any real shift. It highlights the role that education and media, capacity building and science have to play to raise people awareness on sustainable development/IE issues, advance planning and management skills of industrial systems, and develop research on new technologies and theories of sustainable development. In addition, it shows that institutions have to be restructured, regulatory frameworks have to be more effective and realistic, sustainabilityoriented networking has to be established/strengthened among different stakeholders/factories, and funds have to be secured to facilitate governance processes for sustainable development.

Yet, this contextual restructuring, collected from available regional and international literature, is not proposed as a way through which IE could be achieved in Egypt. Indeed, the effective setup is a case-specific contextual one which builds on existing institutional and regulatory frameworks. In addition, embedded in the attempt to bring about an effective setup, the fact that change has to be gradual, coordinated and responsive to contemporary societal characteristics.

\subsection{Societal Will}

Society has to have the will to bring about sustainable development. The political will (Gibbs and Deutz 2007) is part of this, but what really matters is the collective will of all societal groups. Seeking substance not appearance is a key issue in this regard (Geng and Yi, 2005).

\subsection{Media and Education}

Media and education have a significant role to play in making the society willing and mobilised to bring about/accept sustainable development, through:

- Informing the public of the sustainable development objectives and practices.

- Placing greater emphasis on the responsibility and role of individuals, communities and the private sector in supporting progress towards sustainable development/IE (ESCWA, 2003).

- Affirming the inter-connectedness of development, health, and environmental issues as a matter of everyday coverage (Shalaby, 2009d).

- Disseminating cleaner production strategies (Geng and Yi, 2005) and best sustainable practices.

- Exposing environmental violations, following up on enforcement of environmental laws, and even rating manufacturers and producers according to their environmental performance (ESCWA, 2003).

- Forming stronger connections with other civil society sectors, including NGOs, and academic and scientific institutions on sustainability issues (ESCWA, 2003).

- Integrating environmental priorities and sustainability principles into school and university curricula (Shalaby, 2009d). 


\subsection{Capacity Building}

In addition, to public education, further training is needed for those who are directly linked with the incorporation and implementation of IE. Hence, capacity building has emerged as an essential requirement for efficient planning and management of industrial systems. It aims at strengthening institutions, managerial systems and human resources on issues related to not only the environment but also good communication, exchange of information, and interaction among different stakeholders and levels. Capacity building applies to technical planners as well as industry and governmental managers who need continuous update on eco-industrial principles and methods. A successful capacity building program has to observe the following (Geng and Yi 2005):

- Capacity building should directly reflect the needs and overall conditions of the industrial system concerned across different levels/sectors.

- Capacity building should be a long-term process, with clearly stated short, medium and long-term goals which should be evaluated periodically.

- Moreover, functional networks are an effective way to complement traditional technical assistance.

\subsection{Science and New Technologies}

Advanced techno-scientific state is central to finding sustainable solutions in terms of industrial processes and products. Contextualizing the concept of IE and theorizing on its implementation are basically scientific assignments. Improvement of technoscientific conditions is dependent on:

- Pursuing academic research on environmental sciences, sustainable development and IE (Shalaby, 2009d).

- Institutionalising a bigger role for experts in policy making, planning and implementation (Geng and Yi, 2005; Sterr, 2005).

- Inventing and marketing appropriate/context specific environmentally superior solutions/technologies (Geng and Yi, 2005).

\subsection{Institutional Setup}

This subsection lays down the objectives that have to be ideally achieved regarding restructuring institutions to support governance processes for sustainable development ${ }^{6}$.

- Set the system of governance to be society-centric as opposed to statecentric. The former suggests that the state has been progressively hollowed out in a new era of 'governance without government', moving more and more of its policy competences to regional organisations and/or non-state actors (Jordan, 2008). In tune, increase social involvement and institutionalize public consultation and participation (Geng and Yi, 2005). Establish

6 While the proposed setup is ultimately placeless, it cannot be completely separated from the Egyptian contextual socio-cultural and socio-political characteristics. 
permanent and effective national councils/forums with adequate input from governmental institutions and other stakeholders to serve as a mechanism for facilitating policy integration and coordination. In more conclusive words, adopt/support decentralisation (Geng and Yi, 2005) and participatory decision making processes.

- Secure an open access to information to empower participatory decision making (ESCWA, 2003).

- Hold government accountable to people (Shalaby, 2009d).

- Overcome bureaucracy and eliminate corruption to facilitate openness, transparency, and acceptance of change (Shalaby, 2009d).

- Fix artificial segmentation of administrative arrangements (Geng and Yi, 2005) towards more effective integrated ones (ESCWA, 2003).

- Set clear jurisdictions and adequately assign implementation responsibilities to different authorities concerned. Overlapping jurisdictions lead to policy conflicts, program duplication and inefficiency. Further, secure a wider jurisdiction for environmental authorities to address cross-sectoral issues (ESCWA, 2003).

- Resolve power politics (ESCWA, 2003), and coordinate among concerned authorities (Geng and $\mathrm{Yi}, 2005$ ). Facilitate policy integration, coordination and complementarities among institutional bodies seeking to achieve sustainability, i.e., inter-sectoral/inter-ministerial coordination. Provide adequate mechanisms to follow up on policy decisions, resolve deficiencies in policy integration and implementation, and settle disputes (Shalaby, 2009d).

- Set mechanisms to allow governmental institutions to over watch other institutions' actions that affect their areas of competence. Alternatively, nongovernmental forums/committees can over watch non-compliance and nonintegration practices (ESCWA, 2003).

- Advise institutions on means of integrating national sustainable development priorities into their sector strategies, action plans and work programmes (ESCWA, 2003).

- Provide competence and mandate to environmental institutions. Secure the ability of environmental authorities to implement legislations (ESCWA, 2003).

- Enable existing regional environmental institutions to access and engage non environmental ministries on matters of sustainable development in order to handle the task of supporting regional progress towards sustainable development from a multidisciplinary perspective (Shalaby, 2009d).

\subsection{Regulatory setup}

Under the general connotation that a shift from a regulation-based to incentivebased approach (Roberts, 2004), or from a prescriptive to proscriptive code of law (Shalaby, 2010), is a necessity, an effective realistic regulatory setup tuned to IE requires the following:

- Change planning regulations from segregated land uses to allowing mixed harmoniously located areas of industrial and non-industrial activities; and set standards for environmental protection of these mixed areas (Roberts, 2004). 
- Develop new regulations to promote waste reuse (Geng and Yi, 2005), and regulate environmental storage and handling of waste materials (Roberts, 2004).

- Allow the creation of waste sinks or concentrations, and the establishment of reprocessing and energy recovery industries/activities (Roberts, 2004).

- Use economic instruments as proper such as incentives, taxes, effluent charges, prices, and quotas to better allocate and use resources and services (Geng and Yi, 2005). For effective economic instruments, secure a strong monitoring system; a successful voluntary reporting system; a political will to remove subsidies and cancel exemption from complying with national environmental laws and standards; and fully and fairly apply these instruments to all concerned (ESCWA, 2003).

- Enact laws for cleaner production promotion (Geng and Yi, 2005); take measures needed to enforce (ESCWA, 2003) and close loopholes in (Geng and Yi, 2005) laws; and establish effective mechanisms to resolve disputes (Shalaby, 2009d; ESCWA, 2003).

- Enact public right to know and access to information (ESCWA, 2003).

- Revise and amend regulations contradicting the above-mentioned regulatory setup (Shalaby, 2009d).

\subsection{Networking and Information Systems}

Networks among different stakeholders are crucial for coordination inside an industrial park/region in which sustainable cyclic management could be realized. In these networks, industry meets science and politics. Stakeholders exercise interdisciplinary and inter-organisational knowledge and ideas exchange (Sterr, 2005). For Gibbs and Deutz (2005), an eco-industrial park (EIP) should be (in a real sense) a community of, and not just co-located, businesses. It is this networking activity that will potentially encourage materials interchange in the long term and distinguish eco-industrial developments from other, more superficial, initiatives for the greening of industry. For Hewes and Lyons (2008), the development of social relationships is necessary to creating an EIP, not just the technological connections. Indeed, systems make it work, people make it happen. For successful networking, the following have to be considered regarding information systems:

- Support/develop an information system/database that helps plan for/manage optimal reduction, reuse and recycling of resources (Geng and Yi, 2005; ESCWA, 2003; Sterr, 2005).

- Face the challenge of information lack of transparency and incompatibility in order that a useful database could be reached (Sterr, 2005).

\subsection{Funding}

Systematic means to allocate, secure and monitor funding for sustainable development initiatives and environmental protection are a must (Shalaby, 2009d; Geng and $\mathrm{Yi}, 2005)$. This could be achieved through the following:

- Integrate sustainable development initiatives into national budget/plans. 
- Provide enough budgets for environmental authorities and allow local and regional governmental institutions to raise funds and generate income through decentralized revenue collection schemes which capitalize on environmental taxes and pollution charges (ESCWA, 2003).

- Secure complementary funding through international and national partnerships (expanding partnership with local civil society institutions) (ESCWA, 2003).

- Secure additional funds through opening new areas of investment, supporting successful privatization efforts, and expanding economic instruments usage (ESCWA, 2003).

\section{PLANNING FOR IE}

The following presents the steps on national, regional and local levels to be taken to help setup the context and establish EIPs.

\subsection{National Level}

- Nationally, define a platform of sustainable development including IE, taking into consideration local contextual characteristics (Shalaby, 2009d).

- Prepare a National Industrial Ecology Strategy (NIES) ${ }^{7}$ which is multidisciplinary and inter-sectoral. In NIES, identify and prioritise national goals of IE. These goals are concerned with incrementally enabling the context to incorporate IE (Shalaby, 2009d).

- Prepare National Programs of Industrial Ecology (NPIE) that are multidisciplinary and inter-sectoral. Give leverage to NPIE on national budget. In NPIE, set financing, coordination and implementation mechanisms; adequately assign implementation responsibilities to different institutions, and synchronise policy measures; and set targets, triggers and indicators for assessing progress in achieving national IE priorities (ESCWA, 2003).

- In light of NIES and NPIEs, different concerned institutions set out to prepare and implement work plans for funding and implementation (ESCWA, 2003).

- A national interdisciplinary planning research team prepares a comprehensive national urban plan which takes on board IE principles. Preparing this plan is to be informed with contextual and environmental data collected by local and regional authorities. In addition, it is to be developed through back and forth dialogue/consultation with regional authorities (Shalaby, 2009d).

\subsection{Regional level}

On the regional level, an interdisciplinary planning research team has the following tasks to perform regarding IE (Shalaby, 2009d):

\footnotetext{
7 NIES is supposed to be one strategy in a series of integrated national sustainable development
} strategies. 
- Surveying the region to identify actual and potential total and segmented wastewater, materials and energy volumes/flow patterns from natural/ production sources, local manufacturers and partners, reprocessing industries, and current practices of waste management.

- Assessing community attitudes towards integrated manufacturing development planning, mixed industry development, and supportive waste management industries.

- Assessing local government consistency on the application of environmental policies and standards.

- Involving different stakeholders in learning/participatory networking activities to increase awareness of IE and encourage stakeholders to support it; and to build trust, social relationships, cooperation, and collaborative behaviour among stakeholders.

- Preparing a Regional Eco-industrial Plan (REIP) step-by-step with all partners in light of NIES. The plan should indicate implications of the regional growth management strategy and planning schemes for sustainable development on future industry locations; local champion/catalyst industries around which others can congregate; potential industrial clustering; actual/potential spatial concentrations and flows of waste by type; environmental sensitivities of regional locations for waste materials; water and energy processing and reprocessing; potential reprocessing industries and cogeneration firms; a scheme of information systems and networks; different partners roles according to their awareness and attitudes towards IE; and further recommendations on institutional arrangements. The REIP is to be finalised through dialogue and consultation with national and local levels.

- Assessing demands for potential EIPs available in the region.

\subsection{Local Level}

A local planning team for planning an EIP within a REIP will work with the champion/catalyst industry identified to develop other potential partners. This team will work side by side with all local partners on the following tasks (Shalaby, 2009d):

- Designing different scenarios of industrial clustering and technologies to be used, using performance-based appraisal.

- Using systems dynamics and stimulation models to measure the strengths and weaknesses of different designed scenarios quantitatively in a triple bottom line base ${ }^{8}$.

- Evaluating different scenarios operationally, in terms of their symbiosis' environmental impacts and marketability, and choosing best possible ones.

- Working on the chosen scenarios with all partners, with the help and support from local community leaders, and the use of different social relationships, to come up with a case-specific preferable scenario that would lay the

8 Triple bottom line (TBL or "People, Planet, Profit") accounting means expanding the traditional reporting framework to take into account environmental and social performance in addition to financial performance (Wikipedia, 2011b). 
foundations for an EIP that works (in a real sense) as a community of businesses.

- Trust, cooperation and collaborative behaviour need to be developed among establishments before they are prepared to link processes together in ways which have an impact on the economic viability of each establishment.

- Conducting economic and environmental risk assessment of waste and energy by-products' utilisation and exchange for the chosen scenario, for final tuning.

- Working on detailed development plans of the chosen scenario which include locations of business activities, infrastructure, waste storage, transportation and future utility corridors. The latter aims at maximising the collection of industrial by-products, minimising transportation and conveying costs between producer and user establishments. Plans must consider landscaping and buildings' utilities as a means of resource recovery, especially water; flexible tenancy agreements of building or land that will allow for seasonal or variable demand factors; multiple uses of common areas; and community infrastructure as a means of providing learning and leisure in addition to basic services for the community. Plans must also show economically viable development phases, organisational arrangements, recommended implementation processes, and training programs for potential implementation bodies.

- Formulating an effective marketing plan for the chosen EIP.

- The park operator, the waste operator and waste analyser ${ }^{9}$, already members of the local planning team, will continue, as permanent personnel, to monitor the incremental development of the EIP, and prepare supplementary scenarios of waste and energy exchange accordingly within the EIP or with other regional counterparts. These permanent members will be supported by an in-house scientific institution for data collection and analysis, and problem solving.

\section{SYNTHESIS: IE PLANNING FRAMEWORK}

This theoretical paper constructs a conceptual framework of the potential process of founding EIPs. The importance of this framework emerges from being a tool to help evaluate the ability of the current process in Egypt to produce sustainable industrial development. That is utterly needed now, as Egypt is currently planning for an outstanding urban-industrial growth to accommodate double its population up to 2050. The developed framework is composed of three interrelated, interconnected parts: overarching governing understandings, context setup and the planning process towards the realisation of IE.

\footnotetext{
${ }^{9}$ The park operator manages all or part of the infrastructure installations and provides or organizes the provision of the services. Since the operator is the manager of the site he/she will decide whether a new settler company may join the park, and will negotiate the conditions under which it may do so. The waste manager focuses on the companies' internal requirements, while the waste analyser concentrates on the aggregation and analysis of data on a supra-company level or the level of a corporate group. Both are supported by specialised software (Sterr, 2005).
} 
The framework advocates the understanding that IE realisation is a societal task. Society as a whole has to locally define the ambiguous term of IE and take actions to make it viable. These actions, taken inside a continuously changing and complex context to bring about a complex issue, have to be incremental, interdisciplinary, integrated, coordinated and subject to regular update. To insure the integrity and effectiveness of these actions, a context-specific governance system has to be created. One of its powerful tools to guard the realisation of IE is, indeed, a proscriptive, incentive-based code of law, most preferable in such a complex unpredictable context. Also, there should be the understanding that planning process for IE has to consider industrial symbiosis as a primary concern, waste as a source, industrial parks as a means of affording variety and redundancy, and industrial regions as counterparts for industrial parks.

The context has to be geared/structured in light of these understandings. Society, as a whole, has to develop the will to bring about IE; education and media have to raise people awareness on sustainable development/IE issues; capacity building has to advance planning and management skills of industrial systems; and science has to develop research on new technologies and theories of sustainable development/IE. In addition, institutions have to be restructured to facilitate governance processes for sustainable development; regulatory frameworks have to positively respond to IE requirements and be realistic and, effective; and sustainable networking has to be established/strengthened for inter-organisational knowledge/materials exchange among different stakeholders/establishments. Further, funds have to be secured for sustainable development/IE initiatives.

The IE planning process starts with nationally defining a platform of sustainable development, and preparing a national industrial ecology strategy and national programs aimed at setting up the context. In light of the national industrial ecology strategy ${ }^{10}$, and with the participation of all stakeholders, an interdisciplinary national planning team prepares a contextual, comprehensive national urban plan. Within the national urban plan, an interdisciplinary regional planning team develops a regional eco-industrial plan through a learning participatory approach in which champion industries will be identified in terms of industry type and location, taking advantage of regional natural resources and environmental sensitivities, and explores potential waste flows. In tune with the regional eco-industrial plan, a local planning team develops and examines industrial clustering scenarios of the pioneer industrial park to choose the preferable and marketable scenario with the highest industrial symbiosis. The team prepares a detailed plan in such a way that maximises the collection of industrial by-products, minimises transportation and conveys costs between producer and user establishments; and follows up, yet through its permanent personnel, with the development of the project phases to secure industrial symbiosis, whether inside the industrial park or with regional counterparts.

${ }^{10}$ (as well as other national sustainable development coordinated strategies) 


\section{AVENUES FOR FUTURE RESEARCH}

This paper does not propose this framework as a roadmap to bring about industrial ecology in Egypt. Egypt has its unique socio-cultural and socio-political characteristics which will necessitate locally-tailored framework for achieving industrial ecology that builds on existing institutional and regulatory settings. Ideas of good governance and participatory planning processes have faced difficulties in their application in Egypt, and, sometimes, proved unworkable. Their immediate and full application within the current context is doubtful. The lack of theorising upon the current process of founding industrial areas in Egypt adds to this difficulty/doubt.

Having said that, the conceptual framework, constructed in this study, is merely seen as a starting point for further research on how to bring about industrial ecology in Egypt. It stands as an initial structure to help initiate an empirical testing of Egypt's recent endeavours to incorporate sustainable development, and of possible problem solving scenarios. In more details, further empirical research, building on this conceptual framework, is needed to identify:

- The current process through which industrial zones in Egypt are founded, and whether the recent endeavours have made a real shift in practice.

- The influential factors which help give shape to this process and, hence, its outcomes, and the current obstacles which hinder the application of IE. It is these factors and obstacles that have to be dealt with towards a real shift to IE.

- Possible long-term, incremental and context-specific scenarios through which these factors could be changed and these obstacles could be overcome.

Apart from these possible research avenues, the framework could inform a scholarly as well as societal debate on how to set the context and plan for industrial ecology on the national, regional and local levels in Egypt.

\section{Acknowledgments}

Many thanks go to Mohie Shalaby, the PhD researcher at Cardiff University in Wales for the working papers and references he provided, and the fruitful discussions we shared together.

\section{References:}

Cervantes, G. (2007). A Methodology for Teaching Industrial Ecology, International Journal of Sustainability in Higher Education 8, 131-141.

Elabras Veiga, L. and Magrini, A. (2009). Eco-industrial Park Development in Rio De Janeiro, Brazil: A Tool for Sustainable Development, Journal of Cleaner Production 17, 653-661.

ENCC (2009). About Egyptian National Competitiveness Council, [Online] (in Arabic), Egyptian National Council for Competitiveness, Egypt, available at: http://www.encc.org.eg/vision_ar.html (accessed 20/05/2011) 
Erkman, S. (1997). Industrial Ecology: A Historical View, Journal of Cleaner Production $5,1-10$.

ESCWA (2003). Governance for Sustainable Development in the Arab Region: Institutions and Instruments for Moving Beyond an Environmental Management Culture, United Nation Economic and Social Commission for Western Asia - ESCWA.

Geng, Y. and Hengxin, Z. (2009). Industrial Park Management in the Chinese Environment, Journal of Cleaner Production 17, 1289-1294.

Geng, Y. and Yi, J. (2005). Eco-Industrial Development in China. Sustainable Management of Industrial Parks, Proceedings of the German - Chinese Workshop. T. S. Robert Hollander, Wu Chunyou, Geng Yong, Logos Verlag Berlin: 51-67.

Geng, Y., Zhu, Q., Doberstein, B. and Fujita, T. (2009). Implementing China's Circular Economy Concept at the Regional Level: A Review of Progress in Dalian, China, Waste Management 29, 996-1002.

Gibbs, D. and Deutz, P. (2005). Implementing Industrial Ecology? Planning for EcoIndustrial Parks in the USA, Geoforum 36, 452-464.

Gibbs, D., Deutz, P. (2007). Reflections on Implementing Industrial Ecology through Eco-Industrial Park Development. Journal of Cleaner Production 15, 1683-1695.

Hewes, A. and Lyons, D. (2008). The Humanistic Side of Eco-Industrial Parks: Champions and the Role of Trust, Regional Studies: The Journal of the Regional Studies Association 42, 1329-1342.

Jordan, A. (2008). The Governance of Sustainable Development: Taking Stock and Looking forwards, Environment and Planning C -Government and Policy 26 (1): 17-33.

Kim, H. (2007). Building an Eco-Industrial Park as a Public Project in South Korea, the Stakeholders' Understanding of and Involvement in the Project, Sustainable Development 15, 357-369.

Liwarska-Bizukojc, E., Bizukojc, M., Marcinkowski, A. and Doniec, A. (2009). The Conceptual Model of an Eco-Industrial Park Based upon Ecological Relationships, Journal of Cleaner Production 17, 732-741.

Madbouly, M. (2011). The National Urban Plan for 2050, presented at the National Vision Conference of the Engineering Sciences Council, the Specialised Councils Sector, the Scientific Research Academy, held in the National Center for Housing and Building Research, 26-28 ${ }^{\text {th }}$ of November, 2011.

MASRAWY (2010). Rasheed: A Plan to Transfer 900 Industrial Establishments into Eco-friendly Factories, [online] (in Arabic), MASRAWY.com News, Available at: http://www.masrawy.com/News/Egypt/Economy/AF/2010/June/14/1643471. aspx (accessed 20/02/2011)

Roberts, B. (2004). The Application of Industrial Ecology Principles and Planning Guidelines for the Development of Eco-Industrial Parks: an Australian Case Study, Journal of Cleaner Production 12, 997-1010. 
Shalaby, A. (2010). Traditional Urban Process of the Middle East: Lessons in Sustainability, in Lehmann S., AlWaer H., and Al-Qawasmi J. (eds.) Sustainable Architecture \& Urban Development, Volume III, pp.191-208. SAUD 2010: the Seventh International Conference of the Center for the Study of Architecture in the Arab Region, July 12-14, 2010, Amman, Jordan.

Shalaby, M. (2003). The Environmental Dimensions of the Planning of Industrial Areas, the Case of New Cities in Egypt, MSc. Thesis, FURP, Cairo University, Egypt.

Shalaby, M. (2009a). Egypt between Industry and Sustainable Development, unpublished PhD Working Paper, Department of City and Regional Planning, Cardiff University in Wales.

Shalaby, M. (2009b). Sustainable Management of Industrial Zones, unpublished PhD Working Paper, Department of City and Regional Planning, Cardiff University in Wales.

Shalaby, M. (2009c). Review of Literature on Governance for/and Sustainable Development, unpublished PhD Working Paper, Department of City and Regional Planning, Cardiff University in Wales.

Shalaby, M. (2009d). Governance for Sustainable Development in Egypt: Current Situation, Challenges and Proposals, unpublished PhD Working Paper, Department of City and Regional Planning, Cardiff University in Wales.

Singh, A., Lou, H., Yaws, C., Hopper, J., and Pike, R. (2007). Environmental Impact Assessment of Different Design Schemes of an Industrial Ecosystem, Resources, Conservation and Recycling 51, 294-313

Sterr, T. (2005). The Industrial Region as a Promising Unit for Eco-Industrial Development, Sustainable Management of Industrial parks, Proceedings of the German - Chinese Workshop. T. S. Robert Hollander, Wu Chunyou, Geng Yong, Logos Verlag Berlin: 83-99.

Tudor, T., Adam, E., and Bates, M. (2007). Drivers and Limitations for the Successful Development and Functioning of EIPs (Eco-industrial Parks): a Literature Review, Ecological Economics 61, 199-207.

Vermeulen, W. (2007). The Social Dimension of Industrial Ecology: on the Implications of the Inherent Nature of Social Phenomena, Progress in Industrial Ecology, An International Journal 3, 574-598.

Wikipedia (2011a). Industrial Ecology, [online], Wikipedia, the Free Encyclopaedia, available at: http://en.wikipedia.org/wiki/Industrial_ecology (accessed 8/09/2011)

Wikipedia (2011b). Triple Bottom Line, [online], Wikipedia, the Free Encyclopaedia, available at: http://en.wikipedia.org/wiki/Triple_bottom_line (accessed 20/08/2011) 